\title{
PENGARUH MODEL INKUIRI TERBIMBING TERHADAP HASIL BELAJAR SISWA PADA MATERI POKOK SUHU DAN KALOR DI KELAS X SEMESTER II SMA NEGERI I BATANG KUIS
}

\author{
Imelda Rohanna Nadeak dan Ratelit Tarigan \\ Jurusan Fisika FMIPA Universitas Negeri Medan \\ imeldanadeak4@gmail.com
}

\begin{abstract}
ABSTRAK
Penelitian ini bertujuan untuk mengetahui pengaruh model pembelajaran Inkuiri Terbimbing terhadap hasil belajar dan aktivitas belajar siswa pada materi pokok suhu dan kalor di kelas X SMA Negeri I Batang Kuis.Jenis penelitian ini adalah quasi eksperimen dengan desain Two group pretest-postestdesain.Populasi adalah seluruh siswa kelas X Semester II SMA Negeri I Batang Kuis yang terdiri dari 9 kelas. Sampel penelitian diambil 2 kelas yang ditentukan dengan teknik cluster random sampling, yaitu X-1 kelas eksperimen dan X-5 sebagai kelas kontrol, masing-masing berjumlah 33 orang. Untuk pengujian data digunakan instrumen tes hasil belajar, yang berbentuk essay 8 Soal. Uji hipotesis menggunakan uji t.Dari hasil pengujian awal atau pretes siswa dapat diketahui kemampuan awal siswa adalah sama maka $\mathrm{H}_{0}$ diterima, sedangkanpada postes $\mathrm{H}_{0}$ ditolak dan $\mathrm{H}_{\mathrm{a}}$ diterima yakni ada Perbedaan pengaruh model pembelajaran Inkuiri Terbimbing terhadap hasil belajar siswa pada materi pokok suhu dan kalor. Selama proses bembelajaran, nilai aktivitas belajar siswa dikategori nilai cukup aktif. Hasil penilaian ini menunjukkan bahwa penerapan model pembelajaran Inkuiri Terbimbing mampu meningkatkan hasil belajar siswa terhadap nilai koqnitif siswa.
\end{abstract}

Kata kunci :Inquiry Terbimbing, hasil belajar, aktif

\begin{abstract}
This research aimed to determine the effect of quided inquiry learning model of student result and learning activities of the heat and tempereture materials on the first student, semester II, SMA N I Batang Kuis year. This type of research is quasi experiment with two group design, pretest-postest design.the population used throughout on the first student, semester II, SMA N I Batang kuis. Consisted of 9 classes. Samples were taken two classes are determined by random cluster sampling technique, namely the $X^{-1}$ as the class experiment and $X-5$ as the control class. Each numbered 33 people. Date used for testing test instrument learning outcomes, in the form of essay by 8 questions,hypothesis testing using $t$ test. The result of the initial testing of students can be the beginning of students abilities are the same, then Ho accepted,.there is a difference of date processing postest with. So $H_{0}$ rejected and $H_{a}$ accepted that there is an influence of quided inquiry learning model to the learning out comes of students in the subject matter, namely temperature and heat on the first studen,. During the learning process, the activities of students with the category value is quited active. The results showed that the application of quided inquiry learning model can improve of student result on student cognitive value.
\end{abstract}

Keywords : Quided Inquiry model, active and students result 


\section{PENDAHULUAN}

Pembelajaran merupakan salah satu proses yang kompleks dan melibatkan aspek yang realis dengan keadaan. Oleh karena itu untuk menciptakan pembelajaran yang efektif diperlukan berbagai keterampilan. Salah satunya adalah memilih strategi pembelajaran. Tugas dari guru adalah untuk mendorong, membimbing dan memberi fasilitas belajar bagi siswa untuk mencapai tujuan pembelajaran. Guru mempunyai tanggung jawab untuk membantu proses perkembangan siswa, baik aspek-aspek pribadi, seperti nilai dan penyesuaian diri, maupun keterampilan yang harus dikuasai siswa sebagai bekal depannya nanti.

Tujuan pembelajaran fisika adalah untuk dapat membuktikan kebenaran kejadian alam dengan pengaplikasian dan merumuskan teori dasar ilmu alam dalam kehidupan sehari-hari. Tujuan pembelajaran fisika yaitu mempersiapkan siswa agar dapat menggunakan fisika dan sikap sains dalam kehidupan sehari-hari dalam mempelajari dan mengaitkannya dengan berbagai ilmu pengetahuan.

Namun berdasarkan hasil melalui angket dan wawancara dengan bapak Parningotan manullang selaku guru fisika di SMA Negeri 1 Batang Kuis, harapan yang diinginkan tersebut tidak sejalan dengan kenyataan, dimana siswa masih beranggapan bahwa mata pelajaran fisika itu sulit, selain itu mereka menganggap pelajaran fisika itu membosankan dan rumusnya sulit untuk dimengerti sehingga siswa kurang aktif pada saat pembelajaran fisika berlangsung.

Sains sulit, diperkuat oleh pendapat Siti Nurohomah dkk (2011:45) menyatakan bahwa pelajaran fisika adalah pelajaran sains yang terkesan sulit, sehingga siswa lebih dahulu merasa tidak mampu sebelum mempelajarinya. Sedangkan pendapat Eggen, P, dan Kauchak, D, (2011:2) menyatakan bahwa fisika penting untuk diajarkan pada sekolah formal karena merupakan bagian dari kehidupan kita, melekat dengan fenomena jagat raya dan lingkungan kehidupan serta mendukung kemajuan teknologi pada saat ini. Meskipun demikian banyak siswa yang menyatakan IPA fisika merupakan pelajaran yang sulit. Dan pendapat Kanginan, M, (2007) menyatakan bahwa sifat materi pada fisika ada yang abstrak dan ada yang konkret. Materi fisika yang bersifat abstrak sulit untuk divisualisasikan, membuat siswa kesulitan dalam menelaah konsepkonsep fisika yang abstrak.hal ini yang membuat siswa beranggapan bahwa fisika itu sulit dan membosankan.

pada sebagian siswa cepat putus asa jika menghadapi soal yang sulit sehingga hanya menunggu jawaban dari temannya saja, ketika guru menuntut siswa untuk bertanya tentang materi yang sedang dipelajari tidak ada satupun siswa yang bertanya, Hal ini dapat dilihat dari nilai mata pelajaran fisika yang diperoleh siswa lebih rendah dibandingkan dengan nilai mata pelajaran yang lain, dan dibuktikan dengan rata-rata ulangan harian yang diperoleh siswa masih banyak yang dibawah nilai nilai KKM dengan nilai KKM 75 dan juga keaktifitasan siswa pada saat proses balajar mengajar berlangsung. Sejalan dengan hal ini peneliti juga melakukan penelitian awal dengan menyebarkan angket kepada 36 orang siswa kelas X SMA Negeri I Batang Kuis, di dapat $58,33 \%$ siswa berpendapat bahwa pelajaran fisika merupakan pelajaran yang sulit atau tidak menyukai pelajaran fisika dan 41,66 \% siswa yang menyukai pelajaran fisika,sehingga siswa tidak termotivasi untuk aktif ketika belajar fisika.

menghubungkan antara apa yang dipelajari dengan bagaimana pengetahuan tersebut akan dimanfaatkan atau dipergunakan. Tentu saja hal tersebut cenderung membuat siswa terbiasa menggunakan sebagian kecil saja dari potensi atau 
kemampuan pikirnya. Untuk memecahkan masalah pembelajaran tersebut perlu dilakukan upaya antara lain berupa perbaikan pembelajaran yaitu model pembelajaran yang diharapkan mempermudah siswa dalam berpikir kritis dan ketrampilan memecahkan masalah sehingga tercapai hasil yang lebih maksimal

bahwa model pembelajaran

Dari uraian di atas, jelaslah mempengaruhi suasana dan hasil belajar siswa. Penulis juga menemukan bahwa metode pembelajaran yang digunakan guru kurang bervariasi. Padahal diketahui, penggunaan metode yang bervariasi sangatlah diperlukan dalam meningkatkan hasil proses pembelajaran. Guru yang mengajarkan dengan model pembelajaran yang kurang menarik dapat menyebabkan siswa menjadi bosan, pasit, dan tidak kreatif. Oleh karena itu guru dituntut untuk mempergunakan model pembelajaran yang disesuaikan dengan kondisi dan situasi belajar agar tujuan akhir belajar.

Dari beberapa masalah di atas, salah satu model pembelajaran yang dapat dilakukan pada proses pembelajaran disekolah tersebut adalah dengan menerapkan model pembelajaran inkuiry. Menurut gulo (dalam Trianto: 2010; 166), model pembelajaran inkuiri adalah suatu rangkaian kegiatan belajar yang melibatkan secara maksimal seluruh kemampuan siswa untuk mencari dan menyelidiki secara sistematis, kritis, logis, analitis, sehingga dapat merumuskan sendiri penemuannya dengan percaya diri. tercapai. Sasaran utama dari kegiatan pembelajaran inquiry adalah (1) keterlibatan siswa secara maksimal dalam proses kegiatan pembelajaran; (2) keterarahan kegiatan secara logis dan sistematis pada tujuan pembelajaran; dan (3) mengembangkan sikap percaya pada diri siswa tentang apa yang ditemukan dalam proses inkuiri sedangkan menurut Voss (1982,dalam Bruce \& Weil, 1980) menyatakan bahwa inkuiri dapat digunakan untuk pembelajaran sekolah dasar dan menengah,dapat menarik perhatian pembelajaran yang tuli (keterbatasan fisik).

Pembelajaran inkuiri terbimbing yaitu suatu model pembelajaran yang dalam pelaksanaannya guru menyediakan bimbingan atau petunjuk cukup luas kepada siswa. Menurut Syofiah, L, (2012) inkuiri terbimbing biasanya digunakan terutama bagi siswa yang belum berpengalaman belajar dengan pendekatan inkuiri. akan tetapi dikembangkan untuk membantu siswa mengembangkan keterampilan berpikir, pemecahan masalah, dan keterampilan intelektual, belajar berbagai peran orang dewasa melalui pelibatan mereka dalam pengalaman nyata dan menjadi pebelajar yang mandiri. Hasil penelitian terdahulu menunjukkan bahwa inkuiri terbimbing mampu meningkatkan hasil belajar dan keterampilan berpikir siswa. Adapun tujuan penelitian ini yaitu 1).Untuk mengetahui kemampuan belajar siswa yang dibelajarkan dengan model pembelajaran Terbimbing pada materi pokok Suhu dan Kalor kelas X di SMA N I Batang Kuis T.P 2014/2015, 2).Untuk mengetahui kemampuan belajar siswa yang dibelajarkan dengan model pembelajaran langsung pada materi pokok Suhu dan Kalor kelas X di SMA N I Batang Kuis T.P 2014/2015, 3).Untuk mengetahui perbedaan yang signifikan antara kemapuan siswa yang diajar dengan model pembelajaran Terbimbing dengan siswa yang diajar dengan model pembelajaran langsung pada materi pokok Suhu dan Kalor dikelas X SMA Negeri I Batang Kuis T.P 2014/2015 dengan pembelajaran secara konvensional.

\section{METODE PENELITIAN}

Penelitian ini dilakukan di SMA Negeri I Batang kuis Jl. Pancasila Payagambar, selama 5 bulan (maret sampai juli). Populasi dalam penelitian 
adalah seluruh siswa kelas X SMA Negeri I Batang Kuis T.P 2014/2015 yang terdiri atas 9 kelas. Pengambilan sampel dilakukan secaracluster random sampling, diambil 2 kelas yaitu kelas X1 sebagai kelas eksperimen diajarkan model pembelajaran Inquiry Terbimbing dan kelas X-5 sebagai kelas kontrol diajarkan dengan pembelajaran konvensional.Jenis penelitian quasi experiment. quasi experiment

Desain penelitian ini adalah Two Group pre-test-post-test design. Desain penelitian ini dapat dilihat pada tabel 1.

Tabel 1.Two Group pre-test-post-test design(Arikunto, 2010)

\begin{tabular}{|l|c|c|c|}
\hline \multicolumn{1}{|c|}{ Kelas } & Pretes & $\begin{array}{c}\text { Perlak- } \\
\text { uan }\end{array}$ & Postes \\
\hline eksperimen & $\mathrm{T}_{1}$ & $\mathrm{P}$ & $\mathrm{T}_{2}$ \\
\hline Control & $\mathrm{T}_{1}$ & $\mathrm{Q}$ & $\mathrm{T}_{2}$ \\
\hline
\end{tabular}

Keterangan :

$$
\begin{aligned}
& \mathrm{P}=\text { Pembelajaran dengan } \\
& \mathrm{Q}=\text { Pembelajaran dengan }
\end{aligned}
$$
$\mathrm{T}_{2}=$ Postes diberikan setelah perlakuan pada kelas

Pengumpulan data dalam penelitian ini dilakukan dengan metode observasi dan metode tes.. Instrumen yang dipersiapkan yaitu perangkat pembelajaran, lembar pengamatan dan tes hasil belajar berbentuk esaai dengan 8 soal. Sebelum data diolah menggunakan uji t untuk mengetahui pengaruh model pembelajaran inkuiri terbimbing terlebih dahulu dilakukan penilaian pretes, uji normalitas (uji
Lilliefors), uji homogenitas (uji F) dan uji kesamaan rata-rata pretes (uji t).

\section{HASIL DAN PEMBAHASAN}

$\begin{array}{rlr}\text { Mengenai } & \text { identifikasi hasil } \\ \text { pretes dan postes, analisis } & \text { dan } \\ \text { pembahasan, uji hipotesis, } & \text { serta }\end{array}$ keterlaksanaan model pembelajaran Inkuiri Terbimbing. untuk mengetahui pengetahuan atau kemampuan awal siswa pada kelas eksperimen sama dengan kemampuan awal pada kelas kontrol, Pada kelas Eksperimen yang diberikan perlakuan dengan menerapkan model inkuiri terbimbing lebih aktif dalam belajar karena pengetahuan dan keterampilan yang diperoleh siswa dari menemukan sendiri. Model inkuiri terbimbing melatih siswa untuk dapat bekerja sama dalam melakukan percobaan sehingga siswa yang kurang mampu menjadi lebih termotivasi dalam menemukan permasalahan. Pada model inkuiri Terbimbing guru mengarahkan siswa dalam pembentukkan kelompok sehingga suasana pemblajaran lebih kondusif dan dapat mengkondisikan siswa yang belum terbiasa belajar dalam kelompok

Data Nilai Pretes Kelas Eksperimen dan Kelas Kontrol, Data pretes untuk kelas eksperimen dan kelas kontrol dengan jumlah siswa 33 orang,Dapat kita lihat pada tabel 1 
Tabel 2. Nilai Pretes Kelas Eksperimen dan Kontrol

\begin{tabular}{|c|c|c|c|c|c|}
\hline \multicolumn{4}{|c|}{$\begin{array}{c}\text { Data nilai postestes kelas } \\
\text { eksperimen }\end{array}$} & \multicolumn{2}{|c|}{$\begin{array}{c}\text { Data nilai } \\
\text { postes } \\
\text { kelas } \\
\text { kontrol }\end{array}$} \\
\hline Nilai & $\overline{F_{i}}$ & $\begin{array}{l}\text { Rata } \\
\text {-rata }\end{array}$ & Nilai & $\mathrm{F}_{\mathrm{i}}$ & $\begin{array}{c}\mathrm{Nil} \\
\text { ai }\end{array}$ \\
\hline $48-53$ & 0 & \multirow{7}{*}{$\begin{array}{l}79,7 \\
8\end{array}$} & $48-53$ & 2 & \multirow{7}{*}{$\begin{array}{l}65 \\
81\end{array}$} \\
\hline 54-59 & 1 & & $54-59$ & 4 & \\
\hline $60-65$ & 1 & & $60-65$ & 13 & \\
\hline $66-71$ & 6 & & $66-71$ & 2 & \\
\hline $72-77$ & 5 & & $72-77$ & 12 & \\
\hline $78-83$ & 12 & & $78-83$ & 0 & \\
\hline 84-89 & 8 & & 84-89 & 0 & \\
\hline $\begin{array}{c}\text { Jumla } \\
\mathrm{h}\end{array}$ & 33 & & Jumlah & 33 & \\
\hline
\end{tabular}

Data postes untuk mengetahui kemampuan siswa setelah diberi perlakuan atau pengajaran pada kelas postes eksperimen diberi perlakuan dengan model Inkuiri Terbimbing dan pada kelas kontrol diberi perlakuan dengan menggunakan model konvensional, pada hasil belajar siswa pada kelas Eksperimen lebih besar dari hasil belajar kelas kontrol, berarti ada perbedaan hasil belajar dengan menggunakan model pembelajaran Inkuiri terbimbing lebih aktif dalam belajar karena pengetahuan dan keterampilan yang diperoleh siswa dari menemukan sendiri. Model pembelajaran inkuiri terbimbing melatih siswa untuk dapat bekerja sama dalam melakukan percobaan sehingga siswa yang kurang mampu menjadi lebih termotivasi dalam menemukan permasalahan.

Untuk nilai postes kelas eksperimen dan kontrol dengan jumlah siswa 33, dapat kita lihat pada keterangannya tabel II. Karena pada tabel II ini sangat jelas diterangkan hasil nilai postes.
. Tabel 3. Data Nilai Postes Kelas Eksperimen dan Kelas Kontrol tabel 2

\begin{tabular}{|c|c|c|c|c|c|}
\hline \multicolumn{3}{|c|}{$\begin{array}{l}\text { Data nilai pretes } \\
\text { kelas eksperimen }\end{array}$} & \multicolumn{3}{|c|}{$\begin{array}{c}\text { Data nilai pretes } \\
\text { kelas kontrol }\end{array}$} \\
\hline Nilai & $\mathrm{F}_{\mathrm{i}}$ & $\begin{array}{c}\text { Rata } \\
- \\
\text { rata }\end{array}$ & Nilai & $\mathrm{F}_{1}$ & $\begin{array}{c}\text { Rat } \\
\mathrm{a}^{-} \\
\text {rata }\end{array}$ \\
\hline $35-40$ & 2 & \multirow{6}{*}{$\begin{array}{c}62,1 \\
8\end{array}$} & $35-40$ & 2 & \multirow{6}{*}{$\begin{array}{c}57,8 \\
4\end{array}$} \\
\hline $41-46$ & 4 & & $41-46$ & 6 & \\
\hline 47-52 & 2 & & 47-52 & 7 & \\
\hline $53-58$ & 2 & & $53-58$ & 5 & \\
\hline 59-64 & 6 & & $59-64$ & 8 & \\
\hline $65-70$ & 7 & & $65-70$ & 11 & \\
\hline $71-76$ & 10 & & $71-76$ & 0 & \\
\hline Jumlah & 33 & & $\begin{array}{c}\text { Jumla } \\
\mathrm{h}\end{array}$ & 41 & \\
\hline
\end{tabular}

Pengamatan untuk sikap ilmiah siswa dalam kelompok dilakukan oleh dua orang pengamat, pengamatan dilakukan dari mulai pembelajaran sampai akhir pembelajaran pada setiap siswa. Penilaian yang dilakukan oleh observer berdasarkan kriteria yang telah ditetapkan. Penilaian sikap ilmiah dilakukan terhadap masingmasing siswa. Pada pertemuan pertama, hasil pengamatan dua observer diperoleh rata-rata nilai sikap ilmiah seluruh siswa adalah 84,19 dan pada pertemuan kedua rata-rata nilai sikap ilmiah seluruh siswa adalah 85,51. Berdasarkan skor rata-rata dan persentase sikap ilmiah masing-masing siswa dapat disimpulkan bahwa sikap ilmiah siswa termasuk kriteria baik.

Pada siswa mempengaruhi hasil belajar siswa. Semakin aktif siswa dalam belajar maka semakin meningkat hasil belajarnya. Model pembelajaran inkuiri terbimbing dapat digunakan untuk mendorong siswa lebih aktif dalam belajar sehingga siswa akan mendapatkan pemahaman yang lebih baik mengenai materi dan akan lebih tertarik terhadap materi yang disampaikan. Keterlibatan siswa yang aktif terbukti dapat meningkatkan hasil belajar siswa terhadap materi pembelajaran.

Yang menjadi kendala-kendala dalam penelitian adalah 1). ketika membagi siswa dalam kelompok belajar 
masih banyak siswa yang belum terbiasa dengan belajar kelompok sehingga suasana pembelajaran didalam kelas kurang kondusif atau ribut sehingga penggunaan waktu tidak efisien. 2). Masih kurangnya alat dan bahan yang digunakan dalam pelaksanaan percobaan, sehingga dapat mengurangi kemampuan siswa dalam menemukan sendiri permasalahan yang diberikan, 3). peneliti masih kurang menguasai kelas. Untuk mengatasinya 1 ). sebaiknya sebelum menerapkan model pembelajaran inkuiri Terbimbing dalam materi suhu dan kalor, peneliti terlebih dahulu mempersiapkan alat dan bahan sesuai dengan kebutuhan. 2). Disamping itu peneliti belum maksimal dalam mengelolah waktu sehingga semua sintaks kurang efektif saat pelaksanaan proses pembelajaran. 3). Hal tersebut dapat diatasi dengan mengarahkan seluruh siswa agar membagi tugas masing-masing anggota kelompoknya, sehingga pada saat pengumpulan kelompoknya tidak terjadi keterlambatan dan membuang-buang waktu dan siswa dapat melakukan tahap pembelajaran yang selanjutnya dengan baik, peneliti harus bisa menguasai kelas dan menguasai materi yang akan diajarkan pada siswa. Pada Hasil penelitian menunjukkan ada pengaruh model pembelajaran inkuiri Terbimbing terhadap hasil belajar siswa pada Materi Pokok Suhu dan Kalordi Kelas X Semester II SMA Negeri I Batang Kuis.

\section{KESIMPULAN DAN SARAN Kesimpulan}

Berdasarkan hasil analisis yang dilakukan dalam penelitian ini diperoleh kesimpulansebagai berikut : 1). Dapat mengetahui kemampuan belajar siswa yang dibelajarkan dengan model pembelajaran Terbimbing pada materi pokok Suhu dan Kalor kelas X di SMA N I Batang Kuis T.P 2014/2015, 2). Dapat mengetahui kemampuan belajar siswa yang dibelajarkan dengan model pembelajaran langsung pada materi pokok Suhu dan Kalor kelas X di SMA N I Batang Kuis T.P 2014/2015, 3). Untuk mengetahui perbedaan yang signifikan antara kemapuan siswa yang diajar dengan model pembelajaran Terbimbing dengan siswa yang diajar dengan model pembelajaran langsung pada materi pokok Suhu dan Kalor dikelas X SMA Negeri I Batang Kuis T.P 2014/2015 dengan pembelajaran secara konvensional (langsung).

\section{Saran}

Berdasarkan hasil kesimpulan dalam penelitian ini, maka peneliti mempunyai beberapa saran yaitu : 1) Bagi guru bidang studi fisika di SMA Negeri I Batang Kuis agar berkenan mencoba menggunakan model pembelajaran Inquiry Terbimbing dalam melaksanakan kegiatan pembelajaran sebagai salah satu alternatif untuk mningkatkan aktivitas belajar siswa. 2) Kepada peneliti selanjutnya disarankan memilih sekolah yang memiliki fasilitas yang cukup memadai khususnya di laboratorium, sehingga peneliti tidak mengalami kesulitan ketika melakukan penelitian. 3) Bagi siswa, siswa SMA Negeri I Batang Kuis hendaknya selalu melakukan persiapan belajar dan lebih aktif dalam kegiatan pembelajaran agar diperoleh hasil belajar yang lebih baik. 4) Kepada peneliti selanjutnya jika ingin melakukan praktikum hendaknya didampingi oleh guru bidang studi tersebut agar mempermudah peneliti untuk membagikan kelompok supaya siswa tidak ribut diruangan dan dapat menggunakan waktu dengan efisien agar praktikum berlangsung dengan baik.

\section{DAFTAR PUSTAKA}

Arikunto, S, (2010), Metodologi penelitian, Penerbit Bumi Aksara, Jakarta.

Eggen, P, dan Kauchak, D, (2012). Strategi Dan Model 
Pembelajaran, Penerbit PT Indeks, Jakarta.

Kanginan, M, (2007), Fisika SMA untuk Kelas X, Penerbit Erlangga, Jakarta.

Nurohomah, Siti.,Eko Setyandi Kurniawan.,dan Ashari.,(2011), Pemanfaatan Kartun Fisika Sebagai Media Untuk Meningkatkan Motivasi Belajar Pada Siswa Kelas VIIMts N Purworejo. Jurnal Pendidikan Fisika Universitas Muhammadiyah Purworejo Radiasi. Vol.1. No. 1. Hal. 45 (accessed 3/17/2014 4:39 PM).

Syofiah, L, (2012). Pengaruh Model Pembelajaran Inkuiri Terbimbing Terhadap Hasil Belajar Siswa Pada Materi Pokok Usaha Dan Energi Di Kelas Xi Semester I Man Siabu T.P 2012/2013, FMIPA unimed, Medan.

Trianto, (2007). Model-Model Pembelajaran Inovatif Berorientasi Kontruktivis, Prestasi Pustaka, Jakarta. 
